ТРУБЧАНІНОВА К. А., к.т.н., доцент, КУРЦЕВ М. С., к.Т.Н., доцент,

ГАВРИЛЮК М. О., магістрант

(Український державний університет залізничного транспорту)

\title{
Метод розрахунку основних характеристик хвилевідно-щілинної антени
}

Досліджуються щзілинні хвилевідні антенні решітки з метою використання їх не тільки в авіації, а й у житті пересічної людини, наприклад у системах супутникового безпосереднього телевізійного мовлення. У статті наведені формули та розраховано основні характеристики антени, а саме розрахунки резонансних решіток, виконані енергетичним методом.

Ключові слова: хвилевідно-щілинна антена, антенна решітка, резонансна антена, діаграма спрямованості.

\section{Вступ}

Хвилевідно-щілинна антена (ХЩА) належить до класу лінійних (плоских) багатоелементних антен. Випромінювальними елементами таких антен $є$ щілини, прорізані в стінках хвилеводів, об'ємних резонаторів або металевій основі смужкової лінії. На практиці застосовуються ХЩА 3 нерухомою в просторі діаграмою спрямованості (ДС), а також ХЩА 3 механічним, електромеханічним i електричним скануванням.

Основні переваги таких антен: не мають частин, що виступають; можуть бути реалізовані оптимальні ДС, так як закони розподілу поля в розкриві можуть бути різними за рахунок зміни зв'язку випромінювачів 3 хвилеводом; мають порівняно простий пристрій збудження та досить прості в експлуатації [3].

У більшості робіт, присвячених проектуванню ХЩА, не розглядається їх використання для користування у повсякденному житті. Тому метою цісї статті $\epsilon$ дослідження й розрахунок основних характеристик ХЩА та статистичних характеристик випромінювання антени, що дало б змогу застосовувати їх не тільки в авіації, а й у житті пересічної людини, наприклад у системах супутникового безпосереднього телевизійного мовлення.

Щілини, прорізані в стінках хвилеводу, порушуються струмами, що протікають по його внутрішній поверхні. Розподіл поверхневого струму визначається типом хвилі, що розповсюджується у хвилеводі, а інтенсивність збудження щілини залежить від кількості ліній струму, що іiї перетинають. Чим більша проекція щілини на нормаль до ліній струму i чим більша його щільність, тим сильніше збуджується щілина i більша напруженість поля, яке вона випромінює. Таким чином, інтенсивність поля випромінювання можна регулювати шляхом вибору положення щілини на поверхні хвилеводу.

Ця властивість щілинних випромінювачів використовується в розрахунках багатощілинних решіток 3 метою створення необхідного розподілу амплітуд збудження вздовж антени. Одиночний щілинний випромінювач має слабкі спрямовані властивості. Тому на практиці застосовуються багатоелементні щілинні антени, спрямовані властивості яких істотно залежать від кількості щілин, їх взаємного розташування на стінках хвилеводу i режиму роботи передачі лінії. Відповідно до цього розрізняють резонансні і нерезонансні антени [3,4]. У кожному 3 цих класів можлива побудова 3 так званими узгодженими щілинами.

Недоліком щілинних антен $є$ їх вузький діапазон діi. Іноді 3 метою розширення смуги частот збільшують ширину щілини або роблять гантільні щілини. Багатощілинні антени застосовуються також у тих випадках, коли необхідно створити віялову ДС [5].

\section{Основна частина \\ Часто, коли необхідно провести розрахунок антени по заданій ширині головної пелюстки і рівнем бокових пелюсток, може виявитися, що рівно-амплітудна решітка не задовольняє вимоги завдання. У цьому випадку необхідно розрахувати антену 3 нерівномірним розподілом амплітуд збудження. Розподіл Чебишева при цьому є одним 3 вимушених варіантів [2]. \\ Очевидно, цей рівень бокових пелюсток не може бути забезпечений антеною 3 рівноамплітудним збудженням, тому доцільно вибрати антену 3}


нерівномірним розподілом. Вибираємо антену 3 поздовжніми напівхвилевими щілинами на широкій стінці хвилеводу стандартного поперечного перерізу для заданого діапазону хвиль. Відстань $d$ між окремими щілинами розраховується за виразом

$d=\frac{\Lambda}{2}$

Далі визначаємо кількість випромінювальних елементів антени, спочатку знайшовши значення першого кореня полінома Чебишева, а потім за заданим рівнем бічних пелюсток знаходимо кількість щілин $N(N=33)$ :

$x_{01}=\cos \left(\frac{k d}{2} \cdot \sin \theta_{0}\right)$.

Визначаємо довжину антени $L$ та коефіцієнт стиснення $a_{0}$ :

$L=d(N-1)$

$a_{0} \approx 1+0,5\left(\frac{\operatorname{archR}}{N-1}\right)^{2}$

Ширину головної пелюстки ДС на нулях $\theta_{0}$ для антени 3 розрахованими параметрами знайдемо за таким виразом:

$2 \theta_{0}=2 \arcsin \left\{\frac{2}{k d} \arccos \left[\frac{1}{a_{0}} \cos \frac{\pi}{2(N-1)}\right]\right\}$

Основною складністю у розрахунках антен Чебишева $\epsilon$ визначення струмів $I_{v}$ в елементах решітки.

$I_{v}=\left(C_{1} \xi^{4}+D_{1} \xi^{2}+1\right)^{2}$,

де $\xi=2 z / L-$ відносна координатна елемента на осі решітки;

$C_{1}=0,0861 \operatorname{arch} R-0,228$;

$D_{1}=-0,225 \operatorname{arch} R+0,24$.

Кількість щілин в антені непарна, отже, центр решітки випромінювачів повинен перебувати від центра на відстані $(v \times d)$, таким чином маємо:

$\xi=\frac{2 v}{N-1}=\frac{v}{16}=\xi_{v}$, при $-16 \leq v \leq 16$,

$I_{v}=\left(0,17 \xi_{v}^{4}+0,84 \xi_{v}^{2}+1\right)^{2}$

Амплітуди збудження $I_{16}, I_{15}$ крайніх елементів визначаємо за формулою

$I_{16}=I_{15} \frac{a_{0}^{2}}{(N-10)\left(a_{0}^{2}-1\right)}$.

Результати обчислень розміщені в табл. 1 і у вигляді епюри, поданої на рис. 1.

Таблиця 1

Результати обчислень

\begin{tabular}{|c|c|c|c|}
\hline \\
\hline$\xi$ & $I_{v}$ & $v$ & \multirow{4}{*}{$\begin{array}{c}\text { Відстань між щілинами } \\
\text { 0,022 м }\end{array}$} \\
\hline-1 & 0,109 & -16 & \\
\hline$-0,875$ & 0,208 & -14 & \\
\hline$-0,75$ & 0,338 & -12 & \\
\hline 0,625 & 0,411 & -10 & \multirow{4}{*}{$\begin{array}{c}\text { Кількість випромінювальних елементів } \\
\text { антени } 0,988\end{array}$} \\
\hline$-0,5$ & 0,564 & -8 & \\
\hline$-0,375$ & 0,715 & -6 & \\
\hline$-0,25$ & 0,846 & -4 & \\
\hline$-0,125$ & 0,974 & -2 & \multirow{4}{*}{ Довжина антени 0,713 м } \\
\hline 0 & 1 & 0 & \\
\hline 0,125 & 0,974 & 2 & \\
\hline 0,25 & 0,942 & 4 & \\
\hline 0,375 & 0,784 & 6 & \multirow{3}{*}{ Коефіцієнт стиснення пелюстки ДС 1,01 } \\
\hline 0,5 & 0,641 & 8 & \\
\hline 0,625 & 0,487 & 10 & \\
\hline 0,75 & 0,338 & 12 & \multirow{3}{*}{ Ширина головної пелюстки ДС 0,131 } \\
\hline 0,875 & 0,208 & 14 & \\
\hline 1 & 0,109 & 16 & \\
\hline
\end{tabular}




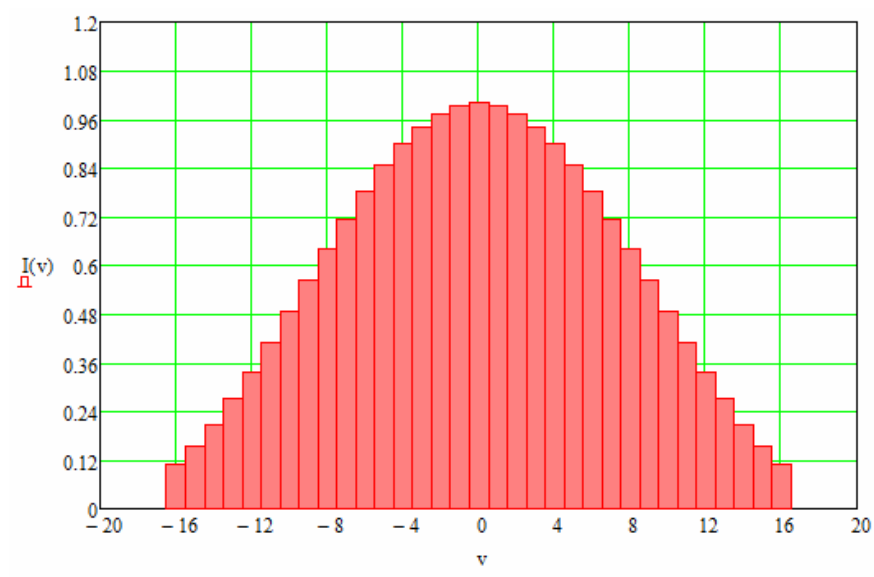

Рис. 1. Амплітудний розподіл за решіткою випромінювачів

Визначення провідності і опорів щілин для багатоелементної антени розраховується при нехтуванні взаємним впливом сусідніх щілин, що $є$ можливим, так як здебільшого щілини розташовуються на відстані, приблизно рівній $\Lambda / 2$, де $\boldsymbol{\Lambda}$ - довжина хвилі у хвилеводі. Тому визначаємо провідність випромінювання $G_{\sum}$, приведену до пучності напруги в щілині за таким виразом:

$$
G_{\sum}=\frac{0,45 \cdot 73,1}{(60 \pi)^{2}}
$$

у свою чергу напруга в пучності $U_{\Pi}$ визначається таким чином:

$$
U_{\Pi}=\sqrt{\frac{P_{\Sigma}}{N G_{\Sigma}}} .
$$

Критичну напруженість поля $E_{\kappa p}$ при нормальному атмосферному тиску розраховуємо так:

$$
E_{\kappa p}=\frac{c p_{B}}{\sqrt[6]{\tau_{u}} \cdot \sqrt[16]{F_{n}}}
$$

Припустиму ширину щілини $Z^{\prime}$ знаходимо за виразом

$$
z^{\prime}=(2 \mathrm{~K} 4) \frac{U}{E_{\kappa p}} .
$$

$$
\Delta l=\frac{42,5 \lambda}{240 \pi\left(\ln \frac{4 \lambda}{\pi z}-0,578\right)}
$$

У цьому випадку резонансну довжину $2 l$ можна визначити як

$$
2 l=\frac{\lambda}{2}-2 \Delta l
$$

Наступним етапом розрахунку $є$ визначення провідності щілин $G_{v}$ :

$$
G_{v}=G_{B x} \frac{I_{v}^{2}}{\sum_{v=1}^{N} I_{v}^{2}}
$$

Цей вираз дає змогу визначити провідність кожної щілини, якщо задані закон розподілу амплітуд порушень уздовж антени і іiі вхідна провідність. Для узгодження вхідна провідність може бути рівна 1. Закон розподілу амплітуд збудження визначається вимогами, що стосуються спрямованих властивостей антени [2].

Визначаємо зсув щілин $x_{1 v}$ щодо середньої лінії широкої стінки хвилеводу:

$$
x_{1 v}=0,732 \arcsin \left(0,784 \cdot \sqrt{G_{v}}\right) .
$$

Результати обчислень наведено в табл. 2 та зображено на рис. 2.

Далі визначимо вкорочення щілини $\Delta l$ : 


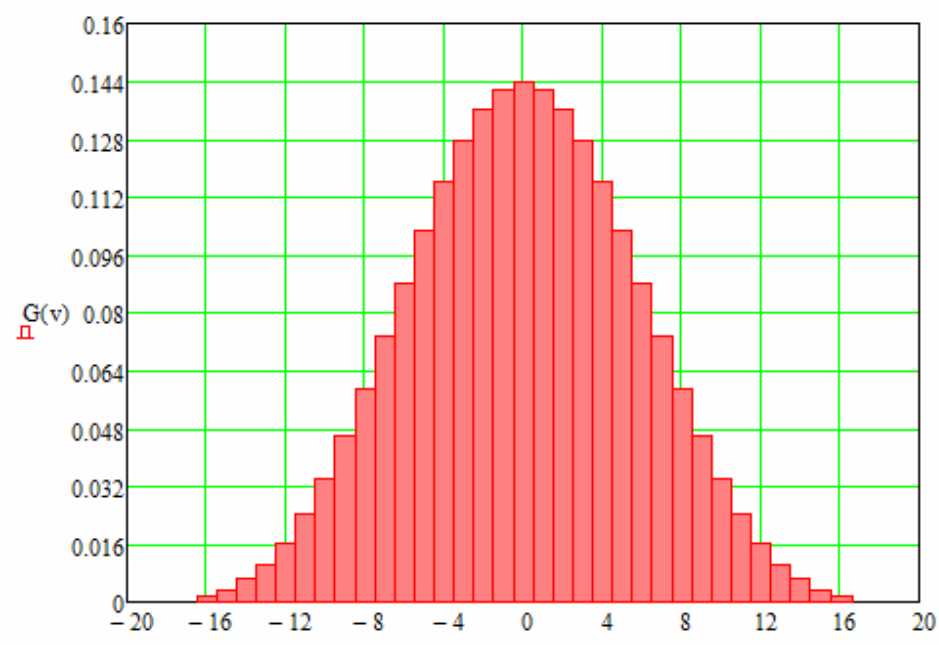

Рис.2. Залежність провідності щілини на діапазоні v

Таблиця 2

Результати обчислень

\begin{tabular}{|c|c|c|c|c|}
\hline$v$ & $G_{v}$ & $I_{v}^{2}$ & $x_{1 v}$ & \multirow{4}{*}{$\begin{array}{c}\text { Провідність випромінення } \\
9,258 \cdot 10^{-4}\end{array}$} \\
\hline-16 & $1,702 \cdot 10^{-3}$ & 0,012 & 0,024 & \\
\hline-14 & $6,236 \cdot 10^{-3}$ & 0,043 & 0,045 & \\
\hline-12 & 0,016 & 0,114 & 0,074 & \\
\hline-10 & 0,034 & 0,237 & 0,106 & \multirow{4}{*}{$\begin{array}{c}\text { Напруга пучності } \\
1,279 \cdot 10^{-3}\end{array}$} \\
\hline-8 & 0,059 & 0,411 & 0,14 & \\
\hline-6 & 0,088 & 0,614 & 0,172 & \\
\hline-4 & 0,116 & 0,808 & 0,198 & \\
\hline-2 & 0,136 & 0,949 & 0,215 & \multirow{4}{*}{$\begin{array}{c}\text { Критична напруженість поля } \\
1,279 \cdot 10^{5}\end{array}$} \\
\hline 0 & 0,144 & 1 & 0,219 & \\
\hline 2 & 0,136 & 0,949 & 0,215 & \\
\hline 4 & 0,116 & 0,808 & 0,198 & \\
\hline 6 & 0,088 & 0,614 & 0,172 & \multirow{3}{*}{$\begin{array}{c}\text { Припустима ширина щілини } \\
9,005 \cdot 10^{-3}\end{array}$} \\
\hline 8 & 0,059 & 0,411 & 0,14 & \\
\hline 10 & 0,034 & 0,237 & 0,106 & \\
\hline 12 & 0,016 & 0,114 & 0,074 & \multirow{3}{*}{$\begin{array}{c}\text { Резонансна довжина } \\
0,012\end{array}$} \\
\hline 14 & $6,236 \cdot 10^{-3}$ & 0,043 & 0,045 & \\
\hline 16 & $1,702 \cdot 10^{-3}$ & 0,012 & 0,024 & \\
\hline
\end{tabular}

Обов'язковим елементом проектування ХЩА $є$ розрахунок діаграми іiі спрямованості, який проводиться у двох областях:

1) в області основної пелюстки:

$\theta \leq \frac{2}{k d} \sqrt{2 \frac{a_{0}-1}{a_{0}}}=0.066$

2) в області бокових пелюсток:

$\left.F(\theta)=\operatorname{ch}(N-1) \sqrt{2\left(a_{0}-1\right)-a_{0}\left(\frac{k d}{2} \theta\right)^{2}}\right\}$.
Результати розрахунків ДС ХЩА показані на рис. 3.

Також необхідно обчислити коефіцієнт корисної дії ККД антени:

$\eta=1-\exp \left[-\sum_{v=l}^{N} \frac{G_{v}}{G_{v} B x}\right]$

ККД антени дорівнює 0,999, що добре узгоджується 3 теоретичними висновками для резонансних щілинних антен. 


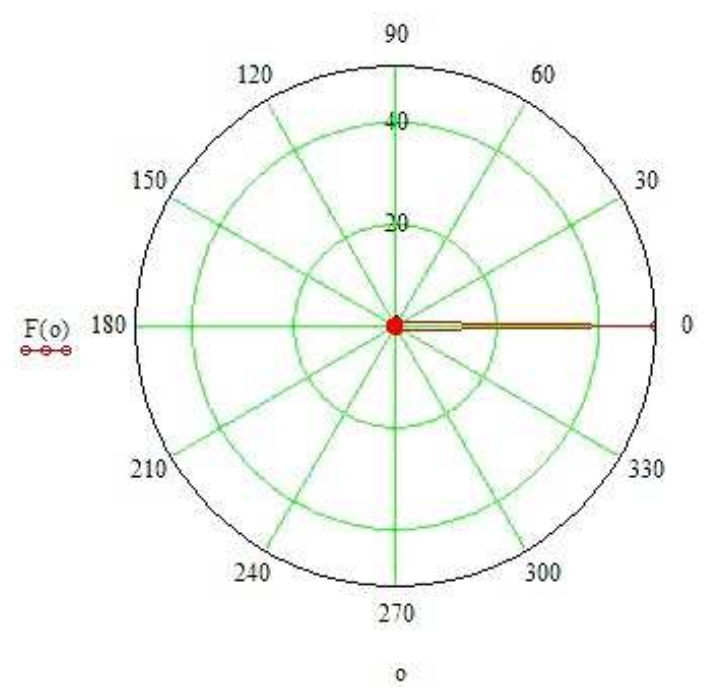

Рис. 3. Епюр ДС ХЩА в площині Н

\begin{tabular}{l}
\hline Висновки \\
\hline розвитком різних радіотехнічних систем та \\
ускладненням розв'язуваних ними технічних завдань \\
зростають вимоги до антенних характеристик. У ряді \\
випадків вони стають суперечливими і зовсім \\
нерозв'язними при спробі розробити нові антени за \\
аналогією з тими, що вже експлуатуються. Наприклад, \\
прагнення збільшити дальність дії і точність \\
визначення кутових координат у радіолокації вимагає \\
збільшення спрямованості антен, а також збільшення \\
швидкості руху променя у просторі, що спричиняє \\
збільшення їх розмірів і мас. Поєднати вимоги \\
збільшення спрямованості та швидкості руху променя \\
в антенах з механічним скануванням не можливо через \\
інерційність їх конструкції. Такі суперечності \\
виникають і при спробах забезпечити високу \\
спрямованість і необхідні частотні й пеленгаційні \\
характеристики. Ці обставини змушують відмовитися \\
від антен традиційного типу для цього класу \\
радіосистем і переходити до антенних решіток. \\
Застосування складних антен у вигляді решіток, що \\
складаються з систем слабкоспрямованих або \\
спрямованих випромінювачів, значно розширює \\
можливості реалізації необхідних характеристик. \\
Резонансна решітка має високу добротність і \\
стабільне випромінювання по нормалі. у статті \\
наведені розрахунки таких решіток, виконані \\
енергетичним методом, загальноприйнятим в \\
інженерній практиці. Цей метод має достатньо високу \\
точність при розрахунку саме резонансних хвилевідно- \\
щілинних антенних решіток або решіток біжучої хвилі \\
з налаштованими щілинами. Недоліком енергетичного \\
методу є те, що він не дає змоги достатньо точно \\
врахувати вплив конструктивних особливостей таких \\
антен: товщину стінки хвилеводу, наявність \\
герметизувальних та захисних покриттів, неідеальність
\end{tabular}

провідності металу, відмінність форми щілин від прямокутної. Через це обгрунтованим $є$ точне електродинамічне моделювання щілинних хвилевідних решіток різного виду для уточнення результатів інженерних розрахунків, яке і $\epsilon$ метою подальших досліджень авторів.

\section{Список використаних джерел}

1. Трубчанінова К.А. Дослідження моделі гібридної радіо-оптичної телекомунікаційної системи. Інформачійно-керуючі системи на залізничному транспорті. 2015. № 6. C. 20-24.

2. Serkov O., Panchenko N., Trubchaninova K., Kurtsev M. Ultra Wideband Communication Technology in the Transport and Logistics Systems. ICTE in Transportation and Logistics 2019. ICTE ToL 2019. Lecture Notes in Intelligent Transportation and Infrastructure. Springer, Cham. 2020. P. 262-270.

3. Klymash M., Pelishok V., Mikhailenich P. Mobile technologies. NVED WAD. Lviv, 2007. 615 p.

4. Прудиус I. Н. Основи антенної техніки. Львів : ЛДУ «Львівська політехніка», 2000. 224 с.

5. Ільницький Л.Я., Савченко О.Я., Сібрук Л.В. Антени та пристрої надвисоких частот: підручник для вузів. Київ, 2003. 495 с.

Трубчанинова К. А., Курцев М. С., Гаврилюк М. А. Метод расчета основных характеристик волноводно-щелевой антенны.

Аннотация. Исследуются щелевые волноводные антенные решетки с целью использования их не только в авиации, но и в жизни обычного человека, например в системах спутникового непосредственного телевизионного вещания. В статье приведены формулы и рассчитаны основные характеристики антенны, а именно расчеты резонансных решеток, выполненные энергетическим методом.

Ключевые слова: волноводно-щелевая антенна, антенная решетка, резонансная антенна, диаграмма направленности.

Trubchaninova K. A., Kurtsev M. S., Havryliuk M. O. Method for calculating the main characteristics of the slotted waveguide antenna.

Abstract. In most works devoted to the design of a waveguide slot antenna, is not considered their use for use in everyday life. Therefore, the aim of this article is the study and calculation of the main parameters of slotted waveguide antennas and statistical characteristics of antenna radiation, which could result not only in aviation but also the use life of the common man, for example, in systems of direct satellite television channels. Single slit emitter has a weak directivity property. Therefore, practical use of multi-element slotted antennas, directional 
properties which significantly depend on the number of cracks, their relative position on the walls of the waveguide and mode of operation of the transmission line. Accordingly, distinguish between resonant and not resonant antennas. Each of these classes, it is possible to build the so-called agreed cracks. The drawback of slot antennas is their narrow scope. Multi-element slot antennas are also used in cases when you need to create a fan chart orientation.

The article presents the formulas and calculated the main characteristics of the antenna, namely the calculation of resonant gratings, made using the energy method. This method has quite high accuracy in the calculation of the exactly resonant waveguide-slot antenna arrays or lattices of the traveling wave with the configured slots. The disadvantage of the energy method is that it doesn't go far enough to consider the impact of design features of such antennas: the thickness of the wall of the waveguide, presence of sealants and protective coatings, non-ideal conductivity of the metal, the difference of the shape of the cracks from the square. For these reasons, it is reasonable accurate electrodynamic simulation of slotted waveguide arrays of different types, with the aim of using it to refine the results of engineering calculations, which is the purpose of further research of the authors.

Keywords: slotted waveguide antenna, grating antenna, resonant antenna, radiation pattern.

Надійила 24.02.2020 p.
Kurtsev Maksym Serhiyovych, PhD. Sc., associate professor, Department of Specialized computer systems of Ukrainian State University of Railway Transport. E-mail: kurtsev_m@ukr.net,_ORCID: https://orcid.org/0000-00017250-4468.

Havryliuk Marharyta, gs of Department of transport communication of Ukrainian State University of Railway Transport.E-mail: gavriluk613@gmail.com.

Трубчанінова Карина Артурівна, кандидат технічних наук, доиент, доиент кафедри транспортного зв'язку Украӥнського державного університету залізничного транспорту, м. Харків, Украӥна. E-mail: tka2@ukr.net, ORCID: http://orcid.org/0000-0003-2078-2647.

Курцев Максим Сергійович, кандидат технічних наук, дочент кафедри спеціалізованих комп'ютерних систем Украӥнського державного університету залізничного транспорту, м. Харків, Украӥна. E-mail: kurtsev_m@ukr.net,_ORCID: https://orcid.org/0000-00017250-4468.

Гаврилюк Маргарита Олександрівна, магістрант кафедри транспортного зв'язку Українського державного університету залізничного транспорту, м. Харків, Україна. E-mail: gavriluk613@gmail.com.

Trubchaninova Karyna, PhD. Sc., associate professor, Department of transport communication of Ukrainian State University of Railway Transport. E-mail: tka2@ukr.net, ORCID: http://orcid.org/0000-0003-20782647. 